\title{
NUTRITIONAL STATUS AND DIETARY HABITS OF WOMEN UNDER 30-60 YEARS OF AGE IN ARIARIA INTERNATIONAL MARKET ABA, ABIA STATE
}

\author{
${ }^{1}$ Oly- Alawuba, N.M and ${ }^{2}$ Munonye, J.O \\ ${ }^{1}$,Department of Nutrition and diatetics, Imo State University Owerri \\ ${ }^{2}$ Department of Agriculture, AE- Federal University Ndufu-Alike Ikwo
}

\begin{abstract}
The nutritional status of an individual is the outcome of a complex interaction between inherited genetic potential and environmental factor. The nutritional status of a people is also to be a sensitive indicator of their overall level of development as a people. The cross-sectional study was undertaken at Ariaria International market and involved 240 women. By using a questionnaire socio-demographic characteristics and market activities of respondents were recorded. Anthropometric measurement were used to assess the body mass index (BMI). Food frequency questionnaire was used to obtain information on the frequency of consumption of foods. One third of the women had chromic disease which is arthritis (24.6) that come as result of overweight and obesity and too much sitting down. Green leafy vegetables $(28.3 \%)$ beverages $(33.3 \%)$, snacks $(28.8 \%)$, root and tubers $(27.1 \%)$ and milk and meat product were the main food groups consumed at least daily. BMI classification showed that $22.9 \%$ and $33.3 \%$ were overweight and obesesed, respectively. Large percentage of the women don't drink alcohol (79.2\%) while other drink alcohol. Prevalence of obesity was hug. Awareness campaigns on need for regular exercise should be emphasized in the market.
\end{abstract}

Keywords: nutritional status, market activities, dietary habits, BMI, women.

DOI: $10.7176 / F S Q M / 92-07$

Publication date: December $31^{\text {st }} 2019$

\section{0 : INTRODUCTION}

Nutritional status is the balance between the intake of nutrients by an organism and the expenditure of these in the processes of growth, reproduction and health maintenance. In a population group, anthropometry is widely used to determine the nutritional status. Anthropometric assessment measures the physical dimension and gross composition of human body at different ages in order to assess the different degrees of nutrition of individuals in relation to their health, predict their performance and reflect their economic and social well-being. Anthropometry assessment of weight and height are the most commonly employed measures of nutritional status in epidemiological studies (Willet, 1990) hence the body mass index (BMI) is mostly used since it is inexpensive, fast and an easy method of assessing the nutritional status of individuals.

The nutritional status of an individual is the outcome of a complex interaction between inherited genetic potential and environmental factors. The nutritional status of an individual is affected by the relationship between individual dietary intake and the bioavailability of the ingested nutrient and the physiological requirement of that individual. (FAO, 1997) observed that knowledge of nutrition situation of a group of individual is necessary when evaluating their present and future states of health and in planning social as well as health activity for them. The nutritional status of a people is also to be a sensitive indicator of their overall level of development as a people (FAO, 1992).

A number of food habits and practices are poor from a nutrition point of view. Nutritional status which on the other hands can be referred to as the state of health as affected by nutrition is an important issue that requires adequate attention. Evidence however has shown that optimal performance, productivity effectiveness and efficiency of an individual are partly a function of the nutrition status of an individual. Since both food habits and nutritional status have far reaching effects on the performance and productivity of every individual, the need for a careful study of the environmental factors affecting these phenomena can never be over emphasized.

Nutrition is the sum total of the processes involved in the taking in and the utilization of food substance by which growth, repair and maintenance of the body are accomplished. Nutrition is also the science that interprets the interaction of nutrients and other substances in food in relation to maintenance, growth, production, health 
and disease of an organism. It includes food intake, absorption, assimilation, biosynthesis, catabolism and excretion.

The saga of human nutrition and the improvement of human health has been reflected in the effort of many scientists who believe that human performances and wellbeing, both physical and mental depends primarily on what is eaten (FAO, 2003). Many people are playing considerable attention to what they eat and with the idea that food intake is closely related with sense of wellbeing, more and more people seek for nutritional information and this advance in knowledge towards nutrition, which has had a great effect on our diet over the last 300 years (Lauden, 2000). As more people are bombarded with facts and figures concerning nutrition, assuming greater responsibility of their health and wellbeing. It is obvious that women also need to have a sound knowledge of nutrition, so as to be sure of what type of food products to consume, even though resources are not available to buy almost all food products.

Malnutrition is a condition of impaired development or function caused by either a long term deficiency or an excess in energy and/or nutrient intake, when supplies are low and the population is large. Under nutrition is common leading to nutritional deficiency disease, such as goiter (from iodine deficiency) and exophthalmia (due to vitamin A deficiency). Insufficient access to foods; poor food habits, poor health services, lack of safe water and sanitation and inadequate child and maternal care, poverty etc. are underlying causes of malnutrition.

The dietary habit of market women may lead to poor and even dangerous lifestyle. Their market activities may influence lifestyle or determine the lifestyle which may eventually affect their nutritional status. Women are ignorant of the consequences, should they continue with such poor dietary habit, the study is therefore undertaken to evaluate the nutritional status and dietary habit of women in Aria-Aria international market Aba, Abia State. The objectives were to determine: the weight and height ; body mass index ; food consumption pattern and the socio-demographic characteristics of the subjects under study.

\section{0: MATERIALS AND METHODS}

Ariaria international market was established in 1976 following a fire outbreak that destroyed the old Ekeoha market in Aba. It is an open air market located in Aba, a city in Abia state south western Nigeria (Okuta et al., 2012). The market was originally sited in a swampy area (Okuta et al., 2015). The market is known for its shoe making and leather works thus making it one of the largest leather shoe-making markets in West Africa with an estimated two million traders. The market is Nicknamed: china of Africa" because of its versatility in the making of wears and leather works (Iremeka et al., 2014). The market cuts across three local government areas, the Aba North, Aba South and Osisioma ( Nwogu et al., 2014).

A cross sectional study design was used to compare the nutritional status and dietary habit of women 30-60years of a group of women in Ariaria international market Aba.It comprises of women age 30-60 years who are marketers in Ariaria International Market, Aba, Abia State.

A random sampling technique was used for the study. The list of the market women constituted the sample frame from which a simple balloting without replacement method was employed.

Sample Size was estimated using the formula: $N=\frac{N}{1+N(e)^{2}}$

Where $\mathrm{n}=$ sample size

$\mathrm{N}=$ population size

$1=$ constant

$\mathrm{e}=$ marginal of error test of significant

Questionnaire was used to screen potential participants and collect pertinent demographic data such as Age, sex, and marital status as well as information on their dietary intake. The questionnaire were validated and pretested. Interview method was also used in gathering further information on their dietary intake.Other instruments used were meter rule and weighing scale. The meter rule was used to obtain the height of the respondent, height of each subject was measured twice and the average was taken. Weighing scale was also used to measure the weight of the respondents.

A structured questionnaires was administered to each women sample in the study area. The questionnaire were personally administered on the respondent because most of them had no formal education. The questionnaire 
was divided into four sections; Demographic and socio-economic data, Anthropometric measurement and Food consumption pattern.

Information on the socio-economy of respondents was obtained through questionnaire. Such information includes occupation, educational level and dietary pattern.

The anthropometric measurement such as height, weight, BMI waist circumference, and circumference was obtained.

Height: A calibrated vertical meter rule was used and measurement recorded to the nearest one centimeter. The subject were asked to remove their foot wears and standing on a flat platform, the hightometre was placed at their back of the head touching the instrument. The need was adjusted comfortably to ensure an erect posture. The hand were made to hang at the side in a natured manner.

Weight: the weights were carried out with a sensitive and portable bathroom scale and reading were taken to the nearest $0.1 \mathrm{~kg}$. The subjects were weighted standing in the middle of the scale, barefooted and their head upright heavy clothing materials were removed.

Determination of Body Mass Index (BMI): it is an indicator that can be used to asks the degree of thinness in an individual, it is defined by WHO (1999) as the body weight ( $\mathrm{kg}$ ) divided by the square of the height (in meter). There are the cut of value used to defined the grades of malnutrition in adults as shown below

\section{Classification of malnutrion in adult BMI}

\begin{tabular}{ll}
\hline BMI & Nutrition status \\
16.00 & Sever underweight \\
$16.00-16.99$ & Moderate underweight \\
$17.00-18.49$ & Mild. Under weight \\
$18.5-24.99$ & Normal (healthy) weight \\
$25.00-29.99$ & Grade I overweight \\
$30.00-39.99$ & Grade II overweight \\
940.00 & Grade III overweight
\end{tabular}

The general food habit and consumption of subject were determined by the administration of the questionnaire. Frequency on food intake and estimated quantities consumed were obtained. The consumption of in-between meals by the subject was also assessed by asking questions on food eaten in-between meals or outside the home. Samples of food mostly consumed were purchased and weighed in order to know the quantity and the cost of meal consumed. The time of consumption of the meal was also obtained

The data collection was analyzed using descriptive statistical tools like frequency, percentage and cumulative, which was done using SPSS (statistical package for social science).

\section{0: RESULTS}

Socio-demographic characteristic

Table 1 revealed that most $(40.8 \%)$ of the respondent were within the age $30-40$ years, majority were married $(65 \%)$. About $(94.6 \%)$ were educated with secondary school holders having the highest percentage $(51.3 \%)$, while $(9.6 \%)$ had no formal education. 
Table 1: personal data of respondents

\begin{tabular}{llll}
\hline \multirow{3}{*}{ Age } & Option & Frequency & $\%$ \\
& $30-40$ & 98 & 40.8 \\
Marital status & $41-50$ & 85 & 35.4 \\
& $51-60$ & 57 & 23.8 \\
& Single & 36 & 15.0 \\
Highest level of education attained & Divorced & 12 & 5.0 \\
& Widow & 36 & 15.0 \\
& Married & 156 & 65.0 \\
& Primary & 65 & 27.1 \\
& Secondary & 133 & 55.4 \\
& Tertiary & 29 & 12.1 \\
& None & 13 & 9.6 \\
\hline
\end{tabular}

Table 2: showed that most of the respondent had normal BMI (40.4\%), the next highest to that is those with more than 25.0-29.9 BMI (overweight) with (33.3\%) while others were obesity and underweight with $22.9 \%$ and $3.3 \%$ respectively.

Table 2. Anthropometry measurement

\begin{tabular}{lll}
\hline BMI & Frequency & Percentage (\%) \\
Underweight & 8 & 3.3 \\
Normal & 97 & 40.4 \\
Overweight & 80 & 33.3 \\
Obesity & 55 & 22.9 \\
\hline
\end{tabular}

\section{Health condition}

Health condition of the respondent revealed that most of the respondent $(66.7 \%)$ had been admitted to the hospital $(60.1 \%)$ always see a medical doctor when sick. Also more than half of the respondent $(40 \%)$ had malaria while $(21.5 \%)$ had worm infection, others were hepatitis and diarrhea $(17.1 \%$ and $4.2 \%)$ respectively, while no respondent had cholera infectious disease. $(39.2 \%)$ of the respondent had the sickness once in three month, while $(24.6 \%, 20.8 \%$, and $15.6 \%)$ respondents had the sickness once in six months, once in year and once in a month respectively. More than half of the respondent had other chronic disease $(43.3 \%)$. The next highest is diabetes mellitus $(20.0 \%)$ followed with the hypertension $(18.3 \%)$, peptic ulcer $(14.2 \%)$, and arthritis $(8.3 \%)$ while none had HIV/AIDS, sickle cell anemia, kidney disease and liver disease, 78 respondent are on a routine drugs which $6.7 \%$ takes anti-hypertension drugs, $5.8 \%$ take oral hypoglycemic drugs, $5.4 \%$ are on aritriheumatric arthritis drugs while $4.2 \%, 3.3 \%, 2.5 \%$ takes antacids, oral contraceptives and insulin injection respectively, $4.6 \%$ takes others 


\begin{tabular}{|c|c|c|}
\hline & Option & Frequency \\
\hline \multicolumn{3}{|c|}{ Have you ever been admitted in a hospital? } \\
\hline \multicolumn{3}{|c|}{ Yes } \\
\hline \multirow[t]{2}{*}{ No } & 160 & 66.7 \\
\hline & 80 & 33.3 \\
\hline \multicolumn{3}{|c|}{ Do you always see a medical doctor when sick? } \\
\hline \multicolumn{3}{|c|}{ Yes } \\
\hline \multirow[t]{2}{*}{ No } & 149 & 60.1 \\
\hline & 83 & 34.6 \\
\hline \multicolumn{3}{|c|}{ What kind of infection disease do you always suffer from? } \\
\hline \multicolumn{3}{|c|}{ Typhoid fever } \\
\hline Malaria & 40 & 16.7 \\
\hline Cholera & 97 & 40.4 \\
\hline Hepatitis & 0 & 0 \\
\hline Diarrhea & 41 & 17.1 \\
\hline \multirow[t]{2}{*}{ Worm infection } & 10 & 4.2 \\
\hline & 52 & 21.7 \\
\hline \multicolumn{3}{|c|}{ How often do you always suffer from these infection? } \\
\hline \multicolumn{3}{|c|}{ Once in a month } \\
\hline Once in three month & 37 & 15.4 \\
\hline Once in six month & 94 & 39.2 \\
\hline \multirow[t]{2}{*}{ Once in year } & 59 & 24.6 \\
\hline & 50 & 20.8 \\
\hline \multicolumn{3}{|c|}{ What kind of chronic disease are you leaving with? } \\
\hline \multicolumn{3}{|c|}{ Hypertension } \\
\hline Diabetes mellitus & 44 & 18.3 \\
\hline HIV/AIDS & 48 & 20.0 \\
\hline Sickle cell anaemia & 0 & 0 \\
\hline Kidney disease & 0 & 0 \\
\hline Liver disease & 0 & 0 \\
\hline Arthritis & 0 & 0 \\
\hline Peptic ulcer & 20 & 8.3 \\
\hline \multirow[t]{2}{*}{ Others } & 24 & 10.0 \\
\hline & 104 & 43.3 \\
\hline \multicolumn{3}{|l|}{ Are you on a routine drugs? } \\
\hline Yes & 78 & 32.5 \\
\hline & 162 & 67.5 \\
\hline \multicolumn{3}{|l|}{$\begin{array}{l}\text { No } \\
\text { If yes which? }\end{array}$} \\
\hline Oral hypoglycemic drugs & 14 & 5.8 \\
\hline Anti -hypertension drugs & 16 & 6.7 \\
\hline Insulin injections & 6 & 2.5 \\
\hline Aritriheumatric arthritis drugs & 13 & 5.4 \\
\hline Oral contraceptics & 8 & 3.3 \\
\hline Antacids & 10 & 4.2 \\
\hline Others & 11 & 4.6 \\
\hline
\end{tabular}

\section{Food habit}

As evident from Table 4 larger percentage (56.7) of the respondent ate thrice a day, 28 subjects ate more than thrice a day. $(29.2 \%)$ of the respondents ate twice a day and $(2.5 \%)$ respondent ate once daily. Also majority of the respondent ate to their satisfaction $(59.6 \%)$ while others did not eat to their satisfaction. It is clearly indicate that $(40.8 \%)$ eat fast food daily $(22.8 \%)$ respondent eat 4-6times weekly, $(21.7 \%)$ of the respondent ate once 3 times weekly $(8.3 \%)$ eats fast food occasionally while $(7.1 \%)$ don't eat in fast food(42.8\%) respondent eats two times or more at home, $(40.3 \%)$ eats once at home and $(6.3 \%)$ eats 3 times or more at home while $(10.0 \%)$ eats nothing at home, $(80.4 \%)$ skip meal while (19.6\%) do not skip meal, also (36.7\%) skip lunch (22.1\%) skip dinner, while $(21.7 \%)$ skip breakfast. $(22.9 \%$ and $22.9 \%)$ of the respondent skip meal because of lack of food and lack of time (11.7\%) skip because of lack of money. (12.1\%) skip meal to reduce weight (6.7\%) skip meal because they have no appetite while (4.2\%) skip meal because they were very tired to eat or to cook. $(59.2 \%)$ of the respondent do not drink alcohol while others drink alcohol, majority of the respondent takes Beer $(16.7 \%)$, while $(8.3 \%)$ takes local wine and $(8.3 \%, 4.2 \%, 2.1 \%)$ take foreign wine, Gin/Whisky and liquor respectively 
and 1.3 takes others. (3.3\%) takes alcohol occasionally (8.3\%) takes alcohols 3-5times weekly (16.7\%) takes alcohol once weekly $(8.3 \%, 4.2 \%)$ takes it daily and monthly. None of the respondents smoked

Table 4: food habit

\begin{tabular}{|c|c|c|}
\hline Option & Frequency & $\%$ \\
\hline \multicolumn{3}{|c|}{ How many times do you eat main meal per day? } \\
\hline Once & 6 & 2.5 \\
\hline Twice & 70 & 29.2 \\
\hline 3times & 136 & 56.7 \\
\hline More than three times & 28 & 11.7 \\
\hline \multicolumn{3}{|c|}{ Do you eat your satisfaction? } \\
\hline Yes & 143 & 59.6 \\
\hline No & 97 & 40.4 \\
\hline \multicolumn{3}{|c|}{ How often do you eat fast food } \\
\hline Daily? & 98 & 40.8 \\
\hline 4-6 times weekly & 53 & 22.2 \\
\hline Once -3times weekly & 52 & 21.7 \\
\hline Occasionally & 20 & 8.3 \\
\hline None & 17 & 7.1 \\
\hline \multicolumn{3}{|c|}{ How many times do you eat from home daily? } \\
\hline 3 times or more & 15 & 6.3 \\
\hline 2 times or more & 102 & 42.5 \\
\hline Once & 98 & 40.8 \\
\hline None & 25 & 10.4 \\
\hline \multicolumn{3}{|l|}{ Do you skip meals? } \\
\hline Yes & 193 & 80.5 \\
\hline No & 47 & 23.75 \\
\hline \multicolumn{3}{|l|}{ Which meal do you skip? } \\
\hline Breakfast & 52 & 21.7 \\
\hline Lunch & 88 & 36.7 \\
\hline Dinner & 53 & 22.1 \\
\hline \multicolumn{3}{|l|}{ Why do you skip meal } \\
\hline Lack of time & 55 & 22.9 \\
\hline Lack of money & 28 & 11.7 \\
\hline Lack of food & 55 & 22.9 \\
\hline No appetite & 16 & 6.7 \\
\hline Very tired to eat or cook & 10 & 4.2 \\
\hline To reduce weight & 29 & 12.1 \\
\hline \multicolumn{3}{|l|}{ Do you take alcohol? } \\
\hline Yes & 98 & 40.8 \\
\hline No & 142 & 49.2 \\
\hline \multicolumn{3}{|c|}{ If yes, which brand do you take? } \\
\hline Local wine & 20 & 8.3 \\
\hline Beer & 40 & 16.7 \\
\hline Foreign wine & 20 & 8.3 \\
\hline Gin/whisky & 10 & 4.2 \\
\hline Liquor & 5 & 2.1 \\
\hline Other & 3 & 1.3 \\
\hline \multicolumn{3}{|c|}{ How often do you take alcohol } \\
\hline Daily & 20 & 8.3 \\
\hline 3-5 time weekly & 20 & 8.3 \\
\hline Once weekly & 40 & 16.7 \\
\hline Monthly & 10 & 4.2 \\
\hline Occasionally & 8 & 3.3 \\
\hline Never & 142 & 59.2 \\
\hline \multicolumn{3}{|l|}{ Do you smoke } \\
\hline Yes & 0 & 0 \\
\hline No & 240 & 100.0 \\
\hline
\end{tabular}




\section{Food consumption pattern}

The respondent consumption of cereal were classified and it was noticed that more than half of the respondent consumed cereal 1 -2times weekly $(42.9 \%)$, the next highest to that is those that consume it daily (28.3), while others consume it 3-4times per week and occasionally with $(14.6 \%)$ and $(14.2 \%)$ respectively. It was also evident from the table that $(39.6 \%)$ respondent consumed legumes 1-2times per week, $(31.3 \%)$ respondent consume legumes occasionally $(19.2 \%)$ respondent consume it 3-4times weekly and others consume (11.7\%) legumes daily. Vegetable consumption by the respondents were also classified and it was noticed that (40.4) respondent consume it 1-2 times weekly, (28.3) respondent consume it daily and were consumed 3-4time per week and occasionally (18.8\%) and (12.5\%) respectively. It was also showed that the respondent consume foods rich in root and tubers (40.0\%) 1-2times per week followed by daily consumption (19.2). consumption of fruit was $(31.3 \%)(27.9 \%),(24.2 \%),(16.11)$ for occasionally, 3 time per week, 1-2times per week and daily, respectively. Beverages were consumed daily (33.3\%), 1-2times per week (32.1) occasionally (18.8\%) and 34 times per week $(15.8 \%)$ by the respondent. Snacks were consumed 1-2times per weekly $(33.3 \%)$, daily (28.8\%), 3-4times per weekly and occasionally $(21.3 \%$ and16.7\%) respectively. Milk and meat products were commonly consumed daily $(31.3 \%),(28.3 \%)$ consumed it $1-2$ times while $(22.1 \%)$ and $(18.3 \%)$ consumed it 3 4 time a week and occasionally respectively.

Table 5: Food Consumption Pattern

\begin{tabular}{lllllllll}
\hline Food group & Daily & & $\begin{array}{l}\text { 1-2times } \\
\text { week }\end{array}$ & $\begin{array}{l}\text { per } \\
\text { 3-4times } \\
\text { day }\end{array}$ & per & Occasionally \\
& Num & $\%$ & Num & $\%$ & Num & $\%$ & Num & $\%$ \\
Cereal & 68 & 28.3 & 103 & 42.9 & 35 & 14.6 & 34 & 14.2 \\
Legumes & 28 & 11.7 & 95 & 39.6 & 46 & 19.2 & 75 & 31.3 \\
Vegetable & 68 & 28.3 & 97 & 40.4 & 45 & 18.8 & 30 & 12.5 \\
Roots/tubers & 65 & 27.1 & 96 & 40.0 & 42 & 17.5 & 47 & 19.6 \\
Fruits & 40 & 16.7 & 58 & 24.2 & 67 & 27.9 & 75 & 31.3 \\
Beverages & 80 & 33.3 & 77 & 32.1 & 38 & 15.8 & 45 & 18.8 \\
Snacks & 69 & 28.8 & 80 & 33.3 & 51 & 21.3 & 40 & 16.7 \\
Milk/meat product & 75 & 31.3 & 68 & 28.3 & 53 & 22.1 & 44 & 18.3 \\
\hline
\end{tabular}

\section{DISCUSSION}

The result of this study showed that half of the respondents were within the reproductive age within the range of less than 40 years and were married. Majority of the respondent $(94.6 \%)$ had one form of education or the other with secondary education accounting for a higher proportion. The level of secondary education reported in this study is similar to 38\% reported among a group of market women in Ikosi-Isheri, Lagos State (Akinloye, 2010).

Based on BMI classification, the prevalence of overweight and obesity combined was $56.3 \%(22.9 \%$ and $33.3 \%$, respectively). The high rate of overweight and obesity maybe a reflection of the sedentary lifestyle of the market women since the better part of their day was made up of setting activities. The rate of obesity reported in this study was lower than $69 \%$ reported among a group of market women in Abeokuta (Mebude, 2010), but higher than $16.3 \%$ reported among female traders in Ibadan. The differences in rates may be related to differences in genetic makeup and socioeconomic status of the three different groups of market women. The high prevalence of overweight and obesity among female traders in this study could also be attributed to cultural norms in Africa where being fat is associated with affluence, beauty and healthy living (Okafor et al., 2015). Most of the respondent has been admitted to the hospital and always see the doctor when sick. Almost all of them had an infection, which malaria has the highest percentage (40.4\%) and diarrhea has the least (4.17\%). Most of the respondent suffer this infection once in three years. (24.58\%) respondent are leaving with arthritis due to overweight and obesity; while $(21.7 \%)$ of respondent are leaving with hypertension $(14.2 \%)$ and diabetes mellitus (7.30\%). Almost half the respondent eat meal 3 times per day (56.7\%). Most of them eat to their satisfaction. $92.9 \%$ of the respondent ate fast food. Daily $40.8 \%$, 4-6 time weekly, once -3times weekly $22.1 \%$, $21.7 \%$ and occasionally $8.3 \%$ respectively. $42.5 \%$ respondent ate 2 times or more at home, one quarter of the respondent ate twice (2times) at home. Almost half of the respondent skip meals. The meals usually skipped by the respondent was breakfast and the main reason for skipping it was due to lack of time to either prepare or eat the meal. The role of women in carrying out household chores coupled with their income generating activities may point to the fact that they may not have the time for food preparation early in the morning. Even when they 
do prepare the meals, their busy schedule may not allow them partake of such meals. (Ming et al., 2006), noted that breakfast is the most important meal of the day that replenishes the body and brain after a night's fast.

Food consumption pattern (Table 5), most of the foods in the food group, were consumed more twice a week. The high rate of consumption of vegetable could be attributed to the fact that the West African diet consists mainly of dishes of green leafy vegetables served as accompaniment to cereals, roots and tubes staples (Oniang'o et al., 2003) fruit consumption was rather low in this study. This corroborates results of (Ganasegeran et al., 2012) which reported that most of their respondent consumed fruit less than three times a week. As pointed out (Oniang'o et al., 2003), low consumption of fruit among Africans from infancy to adult hood could be attributed to factors such as income, educational level, place of residence, ignorance and seasonality. Alcohol consumption was low as most of the respondent consume beer. Too much alcohol is a predisposing factor to obesity and can as well lead to a cluster of other cardiovascular disease. Female nutritional stress begins in childhood and continues through adolescence into adulthood. Nutritional attention is therefore called for throughout the life cycle of women.

\section{CONCLUSION}

The rate of overweight and obesity were high. The market and lifestyle activities could be regarded as sedentary. Also, it is evident that lower percentage (16.7) consumed fruit daily, which in attributed to their poor economic status and ignorance on the important of adequate intake of fruit and vegetables. Larger percentage of the respondents consumed animal protein daily which is an index of good nutritional status.

\section{RECOMMENDATIONS}

Since good nutrition is important and essential to support growth and to meet the physiological needs of women of reproductive age and as inadequate and deficient diet plays a role in the audiology of disease emphasis should be laid on good nutrition among women of reproductive age. The study underscores the need for educational campaign regarding healthier lifestyles, diversification of diet, weight management and control to be conducted regularly in various market.

\section{REFERENCES}

Iremeka, C (2014). Bad Roads; Ariaria Shoe Manufactures Laments Poor Sales New Telegraph Retrieved 25 July 2015.

FAO (1992). The Path To Better Living Promoting Health Diet And Lifestyle In Nutrition, The Global Change Dec 18-20 International Conference On Nutrition.

FAO (1997). Carbohydrate In Human Nutrition. Report Of A Joint Food And Agriculture Organization/WHO Expert Consultation.

FAO (2003). Guideline For Developing An Effective National Food Control System. Rome.

GanaSegeran K; A.1 Dubai; S.A., Qurechi; A.M,.Al-Abed; and S.M Aljunaid (2012). Social And Psychological Factors Affecting Eating Habits Among University Students In A Malaysian Medical School; A Cross Sectional Study. Nutr. J. 11.48 .

Lauden, R. (2000). Birth Of A Morden Diet In Scientific American Pp.76.

Nwogu, M (2014). Ariaria Market. Generating Revenue But No. Infrasture Leadership Retrieved 26 July 2016.

Mebude, A.S (2010). Prevalence Of Obesity Among Market Women In Abeokuta Unpublished B.Sc Thesis). University Of Agriculture, Abeokuta.

Ming M.F; Ying, G.C And Kassim, S. Z (2006). Eating Patterns Of School Children And Adolescents In Kuala Lumpur. Mal, Nutr. 12, 1-10.

Oniang'o, R.K, Mutuku, J.M and Malaba, S.J. (2003). Contemporary African Food Habits and Their Nutritional and Health Implication. Asia Pacific, Clin Nutr., 12(3): 231-236. Piernas, C. And Popkin, B. (2010). Snacking Increasing Among U.S Adult Between 1997 And 206, Journal Of Nutritional, 140(2), 325 332.

Okuta, P (2012). At Last A Breath Of Fresh Air At Ariaria International Market.

Willet, W.C (1990). Overview of Nutritional Epidemiology. In Nutritional Epidemiology, Second Edition, (Oxford, United Kingdom. Oxford University Press), Pp.339-340 